\title{
A MEMÓRIA AFETIVA E A INFÂNCIA DIGNA NA LITERATURA DE CLARICE LISPECTOR
}

\author{
Míriam Coutinho de Faria Alves ${ }^{1}$
}

\begin{abstract}
RESUMO: Este artigo tem por objetivo refletir a partir da perspectiva jusliterária, sobre a construção da memória afetiva enquanto categoria do imaginário dos direitos da criança. Nesse sentido, examina as interligações entre as memórias da infância e a personalidade adulta da personagem Virgínia na obra o lustre de Clarice Lispector para assim tematizar a função da memória afetiva e o direito à infância digna. Diante disso, analisa-se a função das recordações afetivas no processo de formação da identidade o que contribui para investigar como se estruturam as impressões que conformam a construção jurídica dos direitos da criança. Apresenta-se, portanto, o afeto como fundamento à vida digna de modo que a reflexão jusliterária contribui para repensar o imaginário sociojurídico da infância.
\end{abstract}

Palavras-Chave: memória afetiva; Clarice Lispector; direito à infância digna.

\section{CONSIDERAÇÕES INICIAIS}

Benedito Nunes (1989, p. 105) intérprete magistral da obra de Clarice Lispector indica o caráter reflexivo e inquietante de suas personagens e a densa construção que a autora oferece junto ao tema da consciência. De fato, a busca ao profundo reconhecimento da condição humana encontra-se revelada na perspectiva da jusliteratura ao demonstrar elos de ligação entre direito e literatura.

Doutora em Direito pela Universidade Federal da Bahia (UFBA). Professora Adjunta do Departamento de Direito da Universidade Federal de Sergipe (UFS). Membro do Conselho seccional da OAB/Se. Presidente da Comissão de Direito, arte e literatura do IBDFAM/Se. Aracaju, SE, Brasil. CV Lattes: http://lattes.cnpq.br/0824235400578640. Email: miriamfaria2002@yahoo.com.br. 
Os caminhos já apontados por Warat, através do princípio da heteronomia significativa, nos indicam sobre a "existência da pluralidade de centros produtores de sentido" (1995, p. 247) na reflexão jurídica. Streck no texto $O$ senhor das Moscas e o fim da inocência (2008, p. 3) ressalta a importância das disciplinas literárias para o direito. De fato, a narrativa literária coloca os juristas em distintos planos de leitura nos quais a interdisciplinaridade acentua significados ao campo jurídico.

Dessa maneira é interessante notar que, a narrativa literária de Clarice Lispector vai gradualmente provocando reflexões sobre temas jurídicos. Elementos presentes para esta percepção encontram-se revelados ao longo do romance O lustre escrito por Clarice em 1946 e que tem como pano de fundo a composição da memória familiar. Esse romance retrata sentimentos vividos na infância através de sensações, sonhos e fragilidades da personagem Virgínia.

Essas características estão colocadas em distintos momentos do texto literário e relacionam a infância com a ideia de movimento, de trânsito, de espaço de vida que se direciona de uma etapa inicial para outra fase da vida: a adulta. A noção clariceana da infância se traduz, desse modo, a partir da sensação de "estar diante de algo que não existe [...] o futuro" (Lispector, 1999, p. 25). Como nos aponta Merleau-Ponty em fenomenologia da percepção, a sensação nos diz dos modos pelas quais somos afetados pela experiência (2006, p. 23).

Em meio a esse encadeamento, pensar a infância como período da vida humana significa perceber sensações que se desdobram de modo a dar ao ser humano a possibilidade de compreensão da continuidade e cognição do mundo revelando a função imaginativa da racionalidade humana na medida em que as experiências vão sendo intuídas e relembradas no decorrer da vida adulta.

Diante desse imaginário sobre o período infanto-juvenil, o texto literário busca a autenticidade das relações familiares e coloca a personagem central Virgínia, diante da possibilidade de exercer a liberdade ao imaginar transformações nas formas de ver o cotidiano familiar a partir da imagem do lustre objeto central do casarão em que vivera quando criança. 
É nesse ambiente de experimentações que tem como base modelos ordenadores da cultura, que se estabelece a conexão com os direitos da criança relativos ao seu desenvolvimento pleno e saudável. As imagens poéticas do lustre assumem uma forma mediadora entre o pensamento sobre a infância digna e a memória da infância vivida.

Desse modo, essa perspectiva possibilita perceber elementos extrajurídicos que compõem a fenomenologia da infância e aprofunda o diálogo entre a esfera jurídica e o imaginário literário. Com efeito, essa discussão é fundamental pois resgata e dá ênfase aos estudos voltados para filosofia do direito e contribui para uma autenticidade e abertura do conhecimento jurídico na medida em que se discute o papel do intérprete do direito no processo hermenêutico de concretização dos direitos fundamentais.

Nesse sentido, a linguagem literária clariceana observa a infância enquanto lugar de pertencimento. Esse registro se manifesta nos detalhes e ações das personagens. Desse modo, na ideia de infância persiste a noção de continuidade do nascer.Virgínia demonstra que" para nascer as coisas precisam ter vida,pois nascer é um movimento“ ( Lispector, 1999, p. 43).

Dessa forma, a infância é uma construção de sensações e simbologias em que acontecimentos são revelados nos contornos da memória. Isto posto, a memória atua num processo de resgate da identidade familiar e provoca a reflexão das estruturas internas e paradoxais do ser humano nas distintas etapas da vida. Nesse percurso, há uma diferenciação entre a ideia de infância como algo que passa e o fato desse "passar" constituir uma abstração necessária para a compreensão das ações da personagem Virgínia ao "olhar para árvores bem altas, esperar de manhã clara pelo fim da tarde" (Lispector, 1999, p. 26).

Com tal característica, a memória é colocada como fonte de reconhecimento dos fatos vivenciados e ocasiona condições psíquicas presentes na trajetória comportamental adulta. Por intermédio da memória, se alcança o panorama de sensações predominantes na infância que acompanha e determina as interações na vida adulta. Nessa investida, a memória não é um ato isolado e sim construído nas experiências em que o outro participa de forma inacabada pois a reinvenção do passado é acontecimento constante no espírito humano. Nascimento (2012, p. 256) 
nos revela a releitura das narrativas de Clarice Lispector a partir das sensações pensantes da autora.

Esse autor relata a metaforização do mal nos textos de Clarice colocando a natureza humana diante de relações desafiadoras. Ainda nos indica que não se pode conceber o mundo sem o mal" (2012, p. 256). Nos textos de clarice, a experiência sobre o mal está inscrita na infância e nas motivações das personagens, no modo como são percebidos conflitos internos e externos e os recursos utilizados para lidar com as manifestações de angústia evidenciadas através da imaginação poética.

A memória vem a partir de um cenário de multiplicidade de sentidos em torno dos quais surgem questionamentos fundamentais sobre a verdade e circunda paradigmas existenciais. Destarte, o caráter de singularidade da experiência subjetiva da memória afetiva ao repetir-se a nível coletivo corporifica-se na expressão jurídica da infância. Nesse sentido, essas memórias tornam-se questão de reflexão no âmbito jurídico em face do direito ao desenvolvimento saudável da criança.

Ao pensar o direito da criança a partir do acesso à memória afetiva observa-se que a falta de boas sensações na infância, ou o predomínio de sensações conflitantes, agressivas que se relacionam com situações de violência nas relações intrafamiliares adquirem peso na construção da personalidade e desenvolvimento saudável da criança.

$\mathrm{O}$ ambiente em que os fatos ocorrem tem uma especial ligação com o desenvolvimento da criança. Nesse aspecto, a montanha é paisagem sintomática e necessária para Virgínia e marca seu retorno à Granja Quieta já na fase adulta depois de um período na cidade. Santos aponta para à estética da melancolia nas narrativas de Clarice e a partir dela ocorre a "configuração de uma pré-iluminação [...] que se relaciona diretamente com o processo de subida na montanha” (2000, p. 98).

Nesse sentido, as alternâncias entre o amanhecer e o por do sol intensificam as relações entre dois movimentos: infância /vida adulta, pautadas também pelas condições binárias do permitido/proibido. Ainda, nesse sentido, podemos intuir a presença da hierarquia familiar e a partir dessas relações escalonadas observar a ideia de pertencimento que como indica Vesting (2015, p. 90) encontra-se inserida nas tradicionais origens das fontes do direito e contemporaneamente nas repercussões 
constitucionais do direito de família nas relações, entre o código civil e o Estatuto da Criança e do Adolescente.

No tocante aos exemplos, Clarice Lispector alcança com delicadeza a compreensão da dignidade na infância, ao expressar a necessidade de integração ao lar e demonstra a concretude dessas lembranças nas ressonâncias da infância sendo conduzidas por imagens, dentre as quais, a do lustre, na sala do casarão onde Virgínia, Daniel e Esmeralda habitavam quando crianças. Assim, na infância desses irmãos, $O$ lustre marca o conjunto de sensações familiares e de acolhimento, revelando que nessa etapa da vida coexistem sentimentos leves e doces, duros e cruéis.

Através de Virgínia, o sentido da infância é compreendido na busca pelo afeto e desejos sutis de alcançar o mundo. Na fase adulta, Virgínia se depara com as frustrações dos sonhos infantis num mundo não acolhedor. Em outros termos, a memória de Virgínia ao descrever situações de conflito é pautada a partir da relação materna e paterna. Do pai, Virgínia lembra o homem silencioso, dominando a casa e ignorado, subindo escadas" (Lispector, 1999, p. 87).

As formas diversas da infância revelam filosoficamente como destaca Santos, que, "se a cor dos fatos (corpóreos) fosse a mesma, impossível chegar a compreender que há cores (2015, p. 54). Isso significa que os fatos que compõem a história da infância criam impacto sobre a realidade em que as interações familiares ocorrem apontando as formas diversas das interações (colorações) familiares pela estrutura da memória e as modulações dos seus efeitos em cada membro familiar. Nessa investida, como aponta Freud ao descrever a moral sexual cultural, as mulheres, sobretudo, no que tange à construção dos afetos são pautadas pelas autoridades familiares. Assim, muitas vezes a função psíquica correspondente ao estados de enamoramento encontra-se atreladas às sensações familiares dificultando a elaboração do próprio sentir (Freud, 1995, p. 1995).

A respeito da dimensão subjetiva da memória, Sarlo (2007) pondera sobre os usos e abusos desse aspecto na esfera científica. A Convenção do Direito das Crianças ao desenvolvimento da personalidade atenta para as condições de dignidade no contexto das relações familiares. 
Por outro lado, Ariès (1973) investiga à infância na construção histórica do cotidiano europeu. Esse autor ressalta que os ensinamentos na infância eram voltados para o exercício futuro das tarefa e ofícios destinados à formação do adulto na vida social e política. Tais relatos são tratados com riqueza de detalhes sobre a vida das crianças, na história da França, do período medieval aos tempos modernos. Observa-se, por exemplo, que o ato de nomear está vinculado à necessidade de identificação civil a partir de um modelo de Estado moderno.

Portanto, o lugar que a memória cultural ocupa na formação da categoria infância, nos faz atentar para os elementos históricos delineados em torno do imaginário infanto-juvenil. Nesse sentido, o fazer criativo clariceano, pleno de componentes biográficos da infância da escritora, incorpora percepções sobre a natureza e objetos que fazem parte do cotidiano infanto-juvenil brasileiro. Gotlib (1995) ao falar das histórias infantis que marcaram presença na vida da jovem Clarice Lispector, ressalta a importância da leitura como exercício imaginário do real. Na crônica intitulada o primeiro livro de cada uma de minhas vidas, Lispector (1992) revela que o conto do Aladim e do patinho feio foram as primeiras histórias que lhe causaram impacto.

Perguntaram-me uma vez qual foi o primeiro livro da minha vida. Prefiro falar do primeiro livro de cada uma das minhas vidas. Busco na memória e tenho a sensação quase física nas mãos ao segurar aquela preciosidade: um livro fininho que contava a história do patinho feio e da lâmpada de Aladim (Lispector, 1992, p. 72).

Como atesta Gotlib "o que atrai na primeira história é o feio que fica belo. Sente também atração pelo fenômeno da revelação do mistério das coisas: de repente, ser outro" (Gotlib, 1995, p. 104). Em Aladim, o apelo imaginário segue outro caminho, “como a fumaça da lâmpada que, solta no ar, ingressa no impossível que lhe é possível” (Gotlib, 1995, p. 104). Assim, as condições epistemológicas baseadas na literatura infanto-juvenil provocam referências para a compreensão do fenômeno da infância. Contar e narrar histórias vinculadas à tradição oral, fazem parte da vivência literária das crianças que vão incorporando recursos para a compreensão do real. 
Por certo, em Vírginia encontra-se a gênese de Macabea, na figura de uma das personagens mais conhecidas dos leitores de Clarice Lispector, personagem central do romance $A$ hora da estrela, que também apresenta ao leitor sensações e angústias da convivência familiar.

Baseado na perspectiva jusliterária, o alcance social da infância se insere no acesso à realidade e faz eco em determinados aportes culturais. Dentro desse contexto, a construção da subjetividade na infância apresenta a literatura como indicadores de comportamentos sociais tendo em vista que atributos imaginários dos personagens infantis são utilizados no processo de aprendizagem que a criança se identifica e apreende mundos possíveis em que os valores da justiça e injustiça são compartilhados.

\section{A FUNÇÃO IMAGINATIVA DA MEMÓRIA AFETIVA E O DIREITO À INFÂNCIA DIGNA}

Em O lustre, as afetividades são narradas a partir de intuições psíquicas sobre objetos que além de fazerem parte do cotidiano familiar transmigram para a condição imaginária dos afetos. Assim, Virgínia, como fora dito, vive sob o signo da imagem do lustre, objeto presente no casarão onde passara a infância. Ao se despedir da Granja Quieta (sitio da família), vive em tom de nostalgia, pois o passado permanece presente de forma complexa como elo imaginativo deste espaço vital e de retorno necessário.

Observa-se com a personagem que a estrutura da memória possui um caráter de seletividade, "a criança, por exemplo, aprende em primeiro lugar as semelhanças" (Santos, 2015, p. 54). Essas semelhanças dotadas de aspectos dinâmicos e contínuos transparecem no diálogo entre os irmãos Daniel e Virgínia quando eles se interrogam em tom de brincadeiras sobre as aranhas, formigas e cores no quintal da Granja Quieta descobrindo os sentidos do mundo e sua função na realidade do contexto em que vivem. A infância é dotada de um "saber" que se move e se transforma apresentando conteúdos que o direito utiliza para identificar o desenvolvimento pleno $e$ saudável, assim como limites de danos à integridade da criança.

Diante do exposto, a presença da memória afetiva elabora argumentos e recupera a evocação da infância digna nas formas hermenêuticas da construção jurídica. Na memória afetiva de Virgínia, “o lustre se espargia de crisântemos e alegria" (Lispector, 1998, p. 15) ao redor das brincadeiras, do correr e passar pela sala, do olhar que sempre se 
voltava para aquele objeto alto que marcava a presença da sua atmosfera familiar: o lustre. Através dele, "de noite a sala se alumiava numa claridade piscante e doce" (Lispector, 1998, p. 15).

Com efeito, observa-se que o brincar ocupa um papel primordial no desenvolvimento da criança (Winnicott, 1975) a memória das brincadeiras reorganiza acontecimentos ocasionados pelo prolongamento de sensações da infância na vida adulta. Por exemplo, a lembrança do tapete de veludo púrpura do casamento da avó de Virgínia marca na personagem uma sensação de segurança e de densidade no lar.

Clarice Lispector segue a intuição enquanto percepção imediata da presença e anuncia sobre a personalidade de Virgínia sensações moldadas pelo lustre, que assumem para a narradora uma característica da personalidade de Virgínia "Ela seria fluida durante toda vida. Porém o que dominara seus contornos [...], o que a iluminara contra o mundo e lhe dera íntimo poder fora o segredo" (Lispector, 1999, p. 9).

Merece relevo a sensação de segredo que permeia este texto clariceano. Nesse sentido, temos o sigilo como instrumento do poder familiar que em distintas formas se apresenta a partir da sensação de mistério. Esse reconhecimento é um índice que nos faz perceber que a memória nasce do movimento dessas sensações de desvelamento (Dias G, 2012, p. 94). Desse modo, os vínculos afetivos da personagem Virgínia vão gerando um psiquismo que se desenvolve em torno do segredo identificado com a penumbra emitida pelo lustre.

Na descrição da vida em família, as imagens de Virgínia atestam que "o pai jamais falava com Esmeralda e ninguém tocava senão de longe no que lhe sucedera" (Lispector, 1999, p. 17). Diante disso, se estabelecia na situação familiar que algo se passara com a irmã de Virgínia, Esmeralda. A tensão e o segredo familiar se revelam quando Virgínia se dá conta que “o pai olhava para Esmeralda como se ela fosse morta" (Lispector, 1999, p. 18). Rastreando a partir do texto literário essas sensações sobre a irmã Esmeralda, observa-se em Virgínia a consciência de que a existência das relações afetivas são moldadas pela moral familiar.

$\mathrm{Na}$ escuta da personagem, os leitores se inserem no ato de recordar as origens individuais e coletivas das próprias memórias. Como pontua Alves (2001, p. 23) a infância é um processo de construção em meio às camadas 
sociais em seus diversos espaços (família, escola, igreja). Esse espaço vital recria imaginários e possibilita a compreensão das responsabilidades na vida adulta.

Assis Brasil (1969, p. 62) ao abordar o processo criativo clariceano, indica que há na formação das personagens uma tendência da autora a generalizar o personagem e o espaço que constitui o cenário do romance. Dessa maneira, ocorre que ao sair para brincar no espaço de fora da casa, Virgínia tem a sensação de que "toda a casa flutuava, flutuava em nuvens, desligada de Brejo Alto” (Lispector, 1999, p. 16, grifo nosso).

Essa perspectiva de generalização é uma tendência da construção normativa do romance Clariceano. Assim, como o princípio de proteção integral, reconhece a necessidade de alcançar as formas primordiais de apoio afetivo. Teubner (2000) ao evidenciar o saber comum como fonte interpretativa para o direito, enfatiza o papel dos paradoxos simbólicos na racionalidade jurídica; portanto, identificar a origem desses vínculos afetivos torna-se fundamental para se compreender as linhas mais eficazes na prevenção de situações que impliquem danos emocionais à criança.

Por sua vez, o Relatório da situação mundial da Infância de 2015 destaca perspectivas para o enfrentamento da situação de violação de direitos da criança através de sistemas interligados, transversais, que possibilitam contemplar os contextos locais em face das experiências globais (Unicef, 2015).

Essas medidas são analisadas em projetos desenvolvidos a partir do compartilhamento de experiências e dentro de um panorama em que a educação constitui foco fundamental para o desenvolvimento da criança e integra os Objetivos de Desenvolvimento Sustentável (ODS). Em Depoimento sem medo (?) - culturas e práticas não-revitimizantes: uma cartografia das experiências, Santos ao tratar sobre os aspectos da escuta de crianças e adolescentes em situação de violência sexual pontua a necessidade do respeito à diversidade e da especificidade em que essas crianças estão envolvidas.

Mediante tal perspectiva, nota-se que as rememorações de boas lembranças têem efeito positivo e a busca pelo esquecimento seletivo das questões traumáticas e violações merecem ser levadas em consideração. Trindade, ao lançar reflexões sobre o papel das emoções na criação do 
direito ressalta o conteúdo psíquico das normas jurídicas (2010, p.44) delineando que as emoções estão envolvidas nas formas de aceitação ou desaprovação de condutas imersas no plano da cultura.

Nesse sentido, as questões da memória familiar afetam de um modo peculiar o processo de mediação dos conflitos. Também se deve atentar para a reconstrução da autonomia familiar que está limitada por contingentes circunstanciais como a economia e pelo próprio direito. Existem limites éticos e jurídicos a serem respeitados pelo Estado e pelos intérpretes do direito, no que diz respeito aos graus de diversidade e à diferenciação existente em cada contexto familiar específico. De modo que, com o decorrer do tempo, as memórias familiares vão mudando no que diz respeito à forma de reconstrução dos laços familiares.

Nessa linha de reflexão, os chamados direitos subjetivos da criança refletem o processo de desenvolvimento do Estado na formulação e execução de políticas públicas que estejam de acordo com as exigências do texto constitucional para a atuação na esfera infanto-juvenil brasileira.

\section{CONCLUSÃO}

A partir da memória da personagem Virgínia, a escritora Clarice Lispector constrói imagens narrativas da infância na obra $O$ lustre. A teia de imagens que compreende a realidade de Virgínia exerce uma função imaginativa que aguça a compreensão das suas angustias trazendo recursos e elementos para lidar com aspectos fenomenológicos da infância.

Clarice Lispector postula o denso questionamento do viver que se estrutura no fio narrativo da infância de Virgínia, ligado ao acesso à vida e à morte. A esse respeito, cumpre ressaltar a visão simbólica do direito à infância digna considerando o espaço familiar e as formas imaginárias do afeto.

Desse modo, Virgínia ao expressar a experiência da memória afetiva traz aos leitores reflexões sobre a formação da memória no contexto familiar. O exercício dessa consciência aponta para os juristas leitores, formas de refletir sobre os direitos fundamentais da criança. Isso faz com que a figura do leitor enquanto intérprete acompanhe, na dinâmica do texto, ingredientes significativos da função da memória afetiva no espaço familiar. 
Essa experiência consiste num preenchimento do reconhecimento das sensações que a memória alcança na dimensão pessoal e coletiva. Ela, portanto, redefine as sensações emotivas e os estados mentais, reproduzindo seletivamente elementos da intersubjetividade. Dessa maneira, direitos e garantias da criança passam pela função imaginativa da memória afetiva na apreensão do fenômeno da infância.

Já o reconhecimento incorpora vontades, direitos, obrigações e percorre cenários possíveis em que os direitos fundamentais da criança se encontram inseridos, atuando a partir de níveis em que a memória coletiva interage com discursos legislativos propiciadores de políticas públicas e afirmando horizontes de consciência de proteção integral da criança.

Dessa forma, a consciência fenomenal da categoria infância, sob a força dos paradigmas do princípio de proteção integral à criança, é repensada no plano dos direitos humanos. Nessa medida, a leitura dos textos clariceanos desperta visões inovadoras para a compreensão da memória, numa escuta dos direitos fundamentais da criança e à luz da força simbólica da narrativa ficcional.

\section{REFERÊNCIAS}

ARIÉS, Philippe. História social da criança e da família. 2. ed. Rio de Janeiro: Guanabara, 1973.

ASSIS, Brasil. Clarice Lispector: ensaio. Rio de Janeiro: Organização Simões, 1969.

ALVES, Amy A. C. Faria. Figuras de criança versus realidade de adulto. In: ALVES, Amy (Org.). De gente a gente só tem o nome: a mulher no sistema penitenciário em Sergipe. São Cristóvão: Editora UFS, 2001. p. 23-30.

BITTENCOURT, Gilda Neves da Silva. Contos: A vitrina de Clarice Lispector. In: SCHMIDT, Rita (Org.). A ficção de Clarice: nas fronteiras do (im)possível. Porto Alegre: Sagra Luzzato, 2003.

CANDIDO, Antonio. No raiar de Clarice Lispector. In: CANDIDO, Antonio. Vários escritos. 2. ed. São Paulo: Duas cidades, 1977.

CURY, Munir (Coord.), Estatuto da Criança e do Adolescente comentado. 6. ed. São Paulo: Malheiros, 2003, p. 177

FREUD, Sigmund. Ensaio sobre la vida sexual y la teoria de las neuroses. Madrid: Alianza editorial, 1995.

G., Claudio Dias. Clarice Lispector \& Friedrich Nietzsche: um caso de amor fati. Rio de Janeiro: Tempo Brasileiro, 2012. 
GONÇALVES, Tamara Amoroso. Direitos humanos das mulheres e a comissão interamericana dos Direitos Humanos. Trad. e notas de Luciana Yanekawa. São Paulo: Saraiva, 2013

CALVO GONZÁLEZ, José. Derecho y Literatura: intersecciones instrumental, estructural e institucional. In: CALVO GONZÁLEZ, José. Implicación Derecho Literatura; contribuciones a uma teoría literária del derecho. Granada: Comares, 2008.

GOTLIB, Nádia Battella. Clarice. Uma vida que se conta. 3. ed. São Paulo: Ática, 1995.

HOMEM, Maria Lucia. No limiar do silêncio e da letra: traços da autoria em Clarice Lispector. São Paulo: Boitempo: Edusp, 2012.

INSTITUTO MOREIRA SALLES. Edição Especial dos Cadernos de Literatura Brasileira - Clarice Lispector. n. 17 e 18, 2004.

KRISTEVA, Julia. Introdução à semanálise. 3.ed. São Paulo: Perspectiva,2010.

LAGARDE, Marcela. Los cautiverios de las mujeres: madresposas, monjas, putas, presas y locas. 3.ed. México: Universidad Autónoma de México, 2003.

LISPECTOR, Clarice. A descoberta do mundo. Rio de Janeiro: Francisco Alves, 1992.

LISPECTOR, Clarice. A paixão segundo G.H. Rio de Janeiro: Rocco, 1998.

LISPECTOR, Clarice. O lustre. Rio de Janeiro: Rocco, 1999.

MERLEAU-PONTY, Maurice. Fenomenologia da percepção. Trad. de Carlos Alberto R. Moura. 3. ed. São Paulo: Martins Fontes, 2006.

MILL, John Stuart; TAYLOR, Harrier. Ensayos sobre la igualdad sexual. Madrid: Machado Libros, 2000.

MOSER, Benjamim. Clarice, uma biografia. Trad. de José Geraldo Couto. São Paulo: Cosac Naif, 2009.

MÜLLER, $O$ novo paradigma do direito: introdução à teoria e metódica estruturantes. Trad. de Ana Paula Barborsa-Forhmann et al. 3. ed. São Paulo: Editora Revista dos Tribunais, 2013.

NASCIMENTO, Evando. A efêmera memória: Clarice Lispector. In: OLIVEIRA, Maria Clara Castellões de; LAGE, Verônica Coutinho (Org.). Literatura, crítica e cultura I. Juiz de Fora: EdUFJF, 2008. p. 135-145 .

NOLASCO, Edgar César. Clarice Lispector: nas entrelinhas da escritura. São Paulo: Annablume, 2001.

NUNES, Benedito. O drama da linguagem: uma leitura de clarice lispector. São Paulo: Ática, 1989.

OST, François. Contar a lei: as fontes do imaginário jurídico. São Leopoldo: Unisinos, 2009.

SANTOS, Benedito Rodrigues; GONÇALVES, Itamar Batista. Depoimento sem medo (?): culturas e práticas não-revitimizantes; uma cartografia das experiências de tomada de depoimento especial de crianças e adolescentes. São Paulo: Childhood Brasil; Instituto WCF-Brasil, 2008. p. 9. 
SARLO, Beatriz. Tempo passado: cultura da memória e guinada subjetiva. São Paulo: Comp. das Letras, 2007.

SCAVONE, Lucila. Nosso corpo nos pertence? Discursos feministas do corpo. Gênero, v. 10, n. 2, p. 47-62, jan.-jun. 2010.

SOUTO, Kátia Maria Barreto. A política de atenção integral à saúde da mulher: uma análise de integralidade e gênero. SER Social, v. 10, n. 22, p. 161-182, jan.-jun. 2008.

TRINDADE, Jorge. Manual de psicologia jurídica para operadores do direito. 4. ed. Porto Alegre: Livraria do Advogado, 2012.

UNICEF, 2015. Relatório da situação mundial da infância. Disponível em: <http://sowc2015.unicef.org >. Acesso em: 10 set. 2015.

VIGOTSKI, L. S.; LURIA, A. R.; LEONTIEV, A. N. Linguagem, desenvolvimento e aprendizagem. São Paulo: Ícone, 1998.

STRECK, Lenio Luiz. "O senhor das moscas" e o fim da inocência. In: TRINDADE, André Karam; GUBERT, Roberta Magalhães; NETO, Alfredo Copetti (Org.). Direito \& Literatura: ensaios críticos. Porto Alegre: Livraria do Advogado Editora, 2008. p. 113-124.

TEUBNER, Gunther; ZUMBANSEN, Peer. Rechtsentfremdungen: Zum gesellschaftlichen Mehrwert des zwölften Kamels. Zeitschrift für Rechtssoziologie, n. 21, p. 189-215, 2000.

WARAT, Luiz Alberto. Introdução geral ao direito, II. A epistemologia jurídica da modernidade. Porto Alegre: Sergio Fabris, 1995.

WINNICOTT, D. W. O brincar \& a realidade. Trad. de José Octavio Aguiar Abreu. Rio de Janeiro: Imago, 1975.

Idioma original: Português

Recebido: 30/11/15

Aceito: 12/06/16 